\title{
Global seismic network takes to the seas
}

\section{Two systems could plug the ocean-sized gap in earthquake detection.}

BY NICOLA JONES

$\mathrm{M}$ ore than 25 years after its inception, there is hope that the Global Seismographic Network (GSN) will finally live up to its name. The network's 150 or so seismic stations listen for signs of earthquakes and nuclear tests, and help geophysicists to image Earth's interior, but their scope is limited: they are all located on land.

The GSN's vast marine blind spot could soon be eliminated, however, thanks to new, relatively inexpensive equipment that will be field-tested between April and June. For John Orcutt, a geophysicist at the Scripps Institution of Oceanography in La Jolla, California, the prospect of truly global measurements is tantalizing. "Working out how the interior of the planet works is really hard when all your sensors are only on $30 \%$ of the planet's surface," he says.

The GSN, which is run jointly by the Incorporated Research Institutions for Seismology in Washington DC and the US Geological Survey (USGS), was originally intended to blanket the globe with sensors. But installing permanent seismic monitors on the sea floor proved to be too expensive. Thousands of metres of cable are needed to connect the monitors to surface buoys that transmit data in real time, and the bulky equipment must be deployed from costly research ships. "It's the ship time that kills you," says Jonathan Berger, a geophysicist at Scripps who has been involved with the GSN since its inception. Placing and maintaining 2,250 seafloor stations, spaced roughly 400 kilometres apart, would cost between US\$700 million and $\$ 1$ billion over five years, says Guust Nolet, a geophysicist at the University of Nice Sophia Antipolis in France.

Faced with such a steep price tag, researchers have made do with half measures. At any given time, there are a few hundred seismic stations temporarily deployed on the ocean floor, storing data until they can be picked up by ship - usually once a year. The largest number is overseen by the Ocean Bottom Seismograph Instrument Pool (OBSIP), which is funded by the US National Science Foundation (NSF). These temporary stations are useful for retrospective analyses, such as tracing how earthquakes echoed through the Earth and helping to calculate the location of molten plumes inside the mantle. But they cannot be used for anything

\section{UNDERWATER EARS}

New communication technologies could make it cheaper and easier to monitor seismic activity on the sea floor.

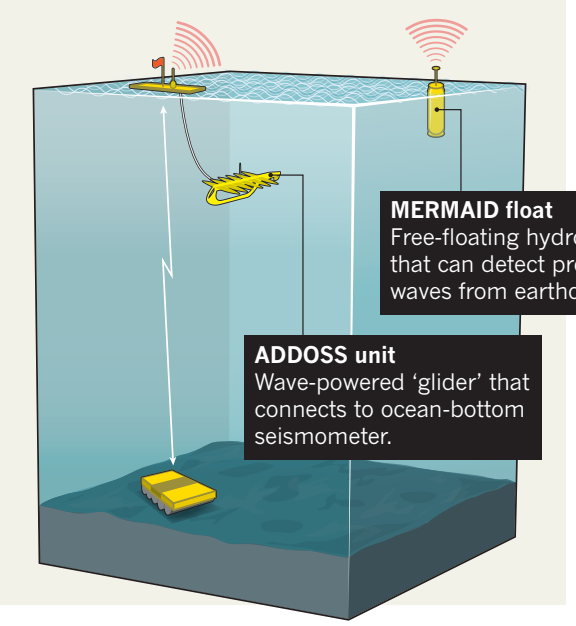

that requires real-time data, such as earthquake monitoring.

For that purpose, a few nations, including Japan and Canada, have installed expensive wired arrays of offshore seismic stations that receive power and send data along fibre-optic cables. The United States will soon install its own array as part of the NSF's Ocean Observatories Initiative (see Nature 501, 480-482; 2013). But for global monitoring, more practical and affordable options are now surfacing.

Berger recently began extended field trials of his Autonomously Deployed Deep-Ocean Seismic System (ADDOSS), which uses 'gliders' that convert wave motion into thrust. Comprised of a submerged portion and a surfboard-sized surface float equipped with solar panels and a satellite positioning system, the gliders are able to wirelessly retrieve data from seismometers on the ocean floor (see 'Underwater ears'). Built by Liquid Robotics of Sunnyvale, California, they are light enough to be installed and maintained by regular ships rather than specialized research vessels. If they experience a problem, the gliders can be programmed to 'swim' to shore. Berger says that his team has also designed, but not yet built, a sleek ocean-bottom seismometer that the gliders can tow to a research site.

"It is a technology that can enable things we have wanted to do for a long time for basic science and earthquake-hazard studies," says
Thorne Lay, a seismologist at the University of California, Santa Cruz, who is not affiliated with the project. Ocean stations should be able to detect small offshore earthquakes that are missed by instruments on land, and they will yield discoveries about Earth's mantle, he says.

Berger's first long-term test of an ADDOSS station this winter was interrupted when a glider experienced problems. He will try again in May or June; if all goes well, he envisages deploying 20 such stations across the world's oceans, roughly 2,000 kilometres apart. The cost of each station - less than $\$ 200,000$ - would be comparable to that of installing and maintaining one of the GSN's existing land-based seismic stations.

A parallel effort pursued by Nolet aims to provide even cheaper ocean coverage. The Mobile Earthquake Recorder in Marine Areas by Independent Divers (MERMAID) system is a set of free-floating buoys that drift with the current. Each buoy carries a hydrophone that can detect pressure waves from large or nearby earthquakes but cannot sense the motions of the sea floor. Nolet estimates that he could blanket the globe with 300 such devices for $\$ 24$ million. Tests of four buoys in the Indian Ocean this winter proved that they can 'hear' through the noise of stormy seas.

In April, Nolet plans to deploy ten more devices to image the mantle plume that lies under the Galapagos Islands. Some previous efforts to map plumes have made use of OBSIP. "It's a great programme, but it's very expensive and it can't do everything," says Cecily Wolfe, a USGS seismologist based in Reston, Virginia, who used the network to investigate the plume beneath Hawaii. Technology such as MERMAID or Berger's ADDOSS programme could one day do similar work more cheaply, and their measurements could also be combined with those of OBSIP to help researchers to recognize and filter out 'contamination' from seismic signals originating outside their survey zone, Wolfe says.

If the new technologies succeed, it will be a remarkable change for science, says Orcutt. But it will be a while before the systems reach their full potential, he adds. "We'll need a couple of decades of observation before things really start to come into focus." - 